\title{
Quiz de Genética e Biologia Molecular - A experiência discente e docente no desenvolvimento de um material didático
}

\section{Genetics and Molecular Biology Quiz - The student and teacher's experience in a development of a teaching material}

\author{
João Miguel Almeida da Silva ${ }^{1}$ \\ Rafael Vieira Canedo ${ }^{1}$ \\ Thomas Alves de Souza Abrantes ${ }^{2}$ \\ Renata Almeida de Souza ${ }^{3}$ \\ Rafael Teixeira dos Santos ${ }^{4}$ \\ Claudia Yamada Utagawa 5
}

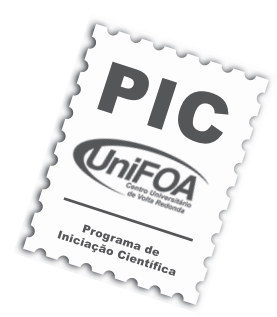

\section{Artigo \\ Original \\ Original \\ Paper}

\section{Palavras-chaves: \\ Metologias de \\ Ensino \\ Tecnologias de Informação}

Ensino de Ciências da Saúde

\begin{abstract}
Resumo
Trata-se de relato da experiência da criação de material didático, interativo, em formato digital, como apoio às aulas da disciplina de Genética e Biologia Molecular (GBM), do curso de graduação em Medicina do Centro Universitário de Volta Redonda - UniFOA - RJ. O material foi desenvolvido por ex-alunos da disciplina, orientados pelos professores, que elaboraram um roteiro de estudo baseado em perguntas e respostas (Quiz) sobre temas específicos. Foi utilizado o programa Macromedia FLASH MX, visando melhor acessibilidade e contextualização do conteúdo. Este artigo tem como objetivo incentivar a reflexão sobre a necessidade de criação de novas ferramentas de ensino que poderiam ser implementadas para facilitar o aprendizado do aluno e tornar o ensino mais dinâmico. A realização deste projeto pelos alunos possibilitou, não só o enriquecimento de conhecimento sobre a temática abordada como também o desenvolvimento de habilidades para a elaboração de material didático, o trabalho em equipe em caráter interdisciplinar, além do aprimoramento de apresentação oral e escrita.
\end{abstract}

\begin{abstract}
This report is about one experience in an education and interactive material creation, in digital format, to support students in Genetics and Molecular Biology (GBM) in Medicine course by Centro Universitário de Volta Redonda -UniFOA, RJ. This software was developed by ex-GBM students with teachers'supervision. It was elaborated a study schedule based on questions and answers like a Quiz about specific topics. It was made on Macromedia FLASH MX program, aiming to join student's value and knowledge with good accessibility. This article has a target to show and stimulate reflection about the importance to create new teaching tools that can be implemented and make the student's apprenticeship easier and the teaching more dynamic. Some data are showed according of the authors' point of view. This project shows importance of learning and improvement of scientific works with bibliographical references. In addition, improve creation of educational material with excellent ability for working team in interdisciplinary context with constant exchange of experiences between groups.
\end{abstract}

Key words:

Teaching Methods

Information

Technologies

Health Science

Teaching.

\footnotetext{
'Discente do Curso de Medicina do Centro Universitário de Volta Redonda - UniFOA

${ }^{2}$ Discente do Curso de Sistemas de Informação do Centro Universitário de Volta Redonda - UniFOA

${ }^{3}$ Doutora em Biologia Parasitária - FioCruz

${ }^{4}$ Docente do Curso de Sistemas de Informação do Centro Universitário de Volta Redonda - UniFOA

${ }^{5}$ Mestre em Pediatria - FMUSP. Docente do Curso de Medicina do Centro Universitário de Volta Redonda - UniFOA
} 


\section{Introdução}

A aprendizagem humana é um processo em constante mudança que, associado ao incremento das informações disponíveis através de novas tecnologias, vem causando uma revolução no pensamento a cerca do conhecimento (Levy1). Na perspectiva da educação formal, ocupa o lugar em relações educativas, que se definem como uma dinâmica entre os sujeitos envolvidos, tendo como objeto de estudo um determinado conjunto de conhecimentos.

A educação deve ser vista, atualmente, num conceito mais amplo, voltado para o desenvolvimento de competências e habilidades que podem ser vivenciadas em ambientes presenciais ou não presenciais. O foco da educação, portanto, sai do professor e se volta para o aluno. Nesse contexto, novas metodologias para apoio didático devem ser pensadas e desenvolvidas objetivando o aprimoramento desse processo.

Todos devemos reconhecer o papel fundamental da utilização de ambientes informatizados na aprendizagem em instituições de ensino, seja fundamental ou superior, para o desenvolvimento intelectual, social e afetivo do indivíduo. Assim, em uma sociedade de bases tecnológicas, com mudanças contínuas, em ritmo acelerado, não é mais possível ignorar as alterações que as tecnologias da informação e da comunicação provocam na forma como as pessoas veem e apreendem o mundo, bem como desprezar o potencial pedagógico que tais tecnologias apresentam quando incorporados à educação. Já é fato que o computador é um instrumento valioso no processo continuado de aprendizagem e, portanto, cabe à escola utilizá-lo de forma coerente com uma proposta pedagógica atual e consistente (Ferreira2).

A publicação deste artigo tem como objetivo relatar a experiência dos autores no processo de criação de material didático em formato digital, como apoio às aulas da disciplina de Genética e Biologia Molecular (GBM), do curso de graduação em Medicina do Centro Universitário de Volta Redonda - UniFOA - RJ.

Ao expor os aspectos referentes às estratégias utilizadas na criação e aplicação do material e na posterior avaliação dos alunos, os autores esperam compartilhar a experiência do desenvolvimento de um material didático de apoio às aulas como uma nova estratégia para a apropriação de conhecimento e incentivar a reflexão sobre a necessidade de criação de novas ferramentas que apoiem ensino.

\section{Relato da Experiência}

Na última década, os campos da Genética e Biologia Molecular têm se tornado cada vez mais amplos e complexos, atraindo diferentes profissionais que necessitam de constante atualização. Temas como Projeto Genoma Humano, Terapia Gênica e Clonagem passaram a ser amplamente debatidos na mídia, aguçando o interesse de todos.

O "Quiz de Genética e Biologia Molecular", um roteiro de estudo baseado em perguntas e respostas sobre temas básicos nessa área de conhecimento, foi concebido para que se tornasse uma nova fonte de referência para os alunos que cursam a disciplina de Genética e Biologia Molecular no UniFOA. O material originou-se de um Projeto de Iniciação Científica desenvolvido por alunos dos Cursos de Medicina e Sistemas de Informação. O Quiz foi desenvolvido em formato digital utilizando a ferramenta ADOBE FLASH MX. Para o desenvolvimento do material, várias etapas foram cumpridas pelos alunos:

1 Decisão de quais temas seriam abordados;

2 Levantamento de bibliografia atualizada;

3 Elaboração do conteúdo em formato de perguntas e respostas (Quiz);

4 Integração com a equipe do Curso de Sistemas de Informação para o desenho do formato digital;

5 Desenvolvimento do material (ver Figura 1 e 2);

6 Aplicação e utilização monitorada do material pelos demais alunos.

A validação do Quiz foi realizada com um público alvo de alunos do $3^{\circ}$ período de Medicina do Centro Universitário de Volta Redonda - UniFOA, que cursavam a disciplina durante três semestres consecutivos. 


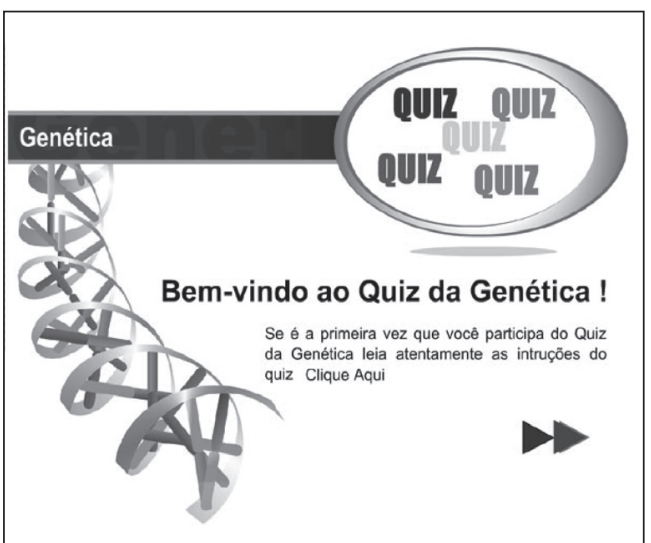

Figura 1 - Página inicial

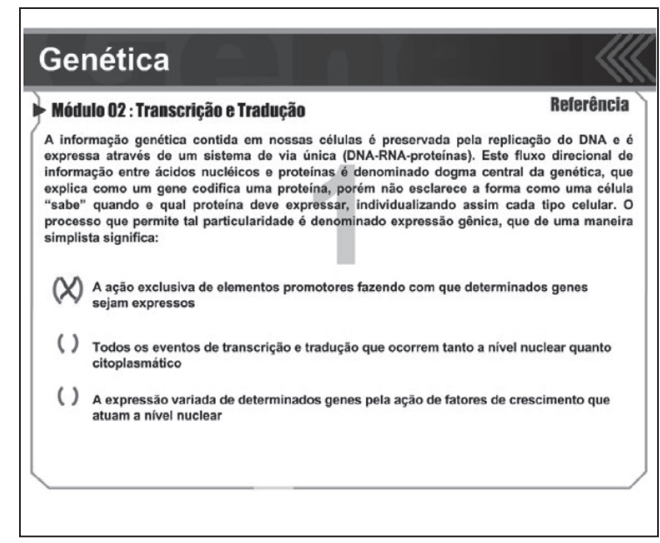

Figura 2 - Apresentação das Perguntas

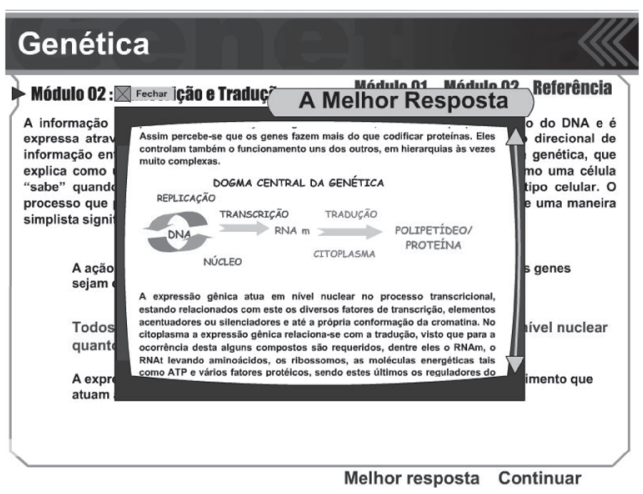

Figura 3 - Apresentação das Respostas

\section{Avaliando a Experiência}

Os autores consideraram essa experiência como valorosa, uma vez que possibilitou o desenvolvimento de diversas competências e habilidades pessoais. Verificou-se um aprofundamento do conhecimento científico, uma melhor contextualização e atualização dos temas. Os alunos autores necessitaram não só de compreender os temas abordados como também de perceberem a inter-relação dos conteúdos de outras disciplinas e descrever, de maneira didática, essa contextualização. Valorizou-se também o desenvolvimento da criatividade, da crítica e da reflexão sobre os temas abordados, uma vez que um dos objetivos almejados para o material didático é que o mesmo fosse lúdico e visualmente atraente.

Outro ganho em relação ao desenvolvimento do projeto foi o desenvolvimento da habilidade de leitura, da escrita e da oratória, com utilização adequada da terminologia científica, inclusive em língua estrangeira. $\mathrm{O}$ trabalho, em seus diversos estágios, foi apresentado em Congressos de Educação Médica, sendo necessária a produção de resumos e banners, agregando valor ao currículo dos alunos. $\mathrm{O}$ trabalho em equipe, em caráter multiprofissional foi uma das experiências mais enriquecedoras. $\mathrm{O}$ desafio maior foi fazer com que alunos de cursos de áreas diversas chegassem a um produto comum. Para isso, o aluno de Sistemas de Informação necessitou "incorporar" a terminologia e os conceitos de ciências da saúde ao seu universo e os alunos de medicina compreenderem como as ferramentas de tecnologia de informação poderiam ser utilizadas e quais eram suas limitações. Além disso, eram necessárias reuniões periódicas do grupo para resoluções de problemas e tomada de decisões em relação à elaboração do material. Por fim, os alunos do Projeto participaram como monitores da disciplina, um estímulo à atividade docente, dirimindo dúvidas durante a aplicação do Quiz nos laboratórios de informática.

Em relação ao projeto desenvolvido, um dos aspectos interessantes que merece ser destacado é a característica do próprio material didático, em que os alunos podem aprender jogando, ou seja, respondendo a questões inseridas no programa da disciplina e testando seus conhecimentos, através de erros e acertos, de uma forma divertida e interativa, fora das salas de aula (Allery3).

As perguntas são apresentadas no formato de Quiz, de maneira a despertar a curiosidade e o raciocínio dos alunos, baseadas no método de resolução de problemas, com situações problema em que os participantes podem aplicar seus conhecimentos à prática médica. Dessa maneira, o material torna-se muito mais atraente do que a forma convencional de estudo, quando os estudantes se deparam com textos enormes e por muitas vezes cansativos, com muita informação teórica, sem fornecer muita correlação com a aplicabilidade clínica.

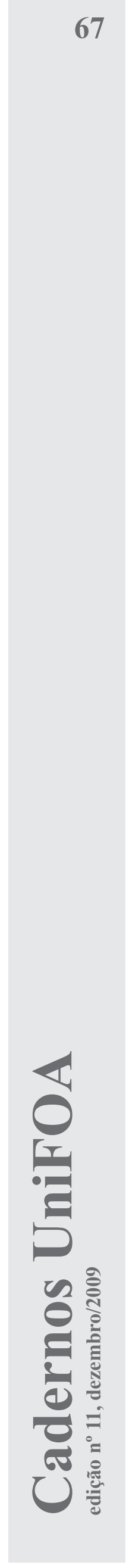


Do ponto de vista do professor, a experiência traz novas possibilidades de interação com o aluno e necessidade de adaptação a essa nova estratégia de ensino. É um erro pensar que as novas tecnologias, principalmente o computador e a internet substituirão os professores nas salas de aula. Na verdade, o projeto desencadeou aprendizagens tanto discentes como docentes, estabelecendo-se um processo dialógico e de mútua formação com os alunos (Ferreira2, Magalhães4).

\section{Conclusão}

O aprimoramento dos alunos autores do Projeto não foi apenas no âmbito do desenvolvimento dos temas em questão, mas principalmente de capacidades e habilidades que poderão ser aplicadas em outras disciplinas e em suas atividades profissionais.

Os autores acreditam também que a elaboração do Quiz de Genética e Biologia Molecular (GBM), principalmente associado aos recursos da Informática, forneceram subsídios para o aprimoramento didático-pedagógico dos próprios alunos e também dos professores, contribuindo para a reformulação da visão do processo de ensino-aprendizagem, já que a inversão do papel do aluno, transformando-o temporariamente em "professor-autor", otimiza o processo de aprendizagem dos demais alunos. Sendo assim, os autores demonstram ter alcançado boa parte de seus objetivos iniciais, gerais e específicos, observando a importância da continuidade do projeto, e aperfeiçoamento do material desenvolvido, reforçando ainda mais a necessidade de criação de novas ferramentas de ensino que, como o Quiz, possam ser construídas coletivamente, constantemente atualizadas e direcionadas para as deficiências e dificuldades individuais de cada aluno.

Conclui-se que, alternativas viáveis e possibilidades interessantes de busca de novas ferramentas educativas significantes para os estudantes devem ocorrer baseados no compromisso com o aprendizado e formação dos profissionais, se possível, de maneira lúdica.

\section{Referências}

LÉVY, P. As tecnologias da inteligência: o futuro do pensamento na era da informática. Tradução de Carlos Irineu da Costa. São Paulo: Editora 34, 1993.

\section{FERREIRA, V. F. As tecnologias interativas} no ensino. Quím. Nova, São Paulo, v. 21, n. 6, Nov. 1998. Disponívelem: <http://www.scielo. br/scielo. php?script $=$ sci_arttext\&pid $=\mathrm{S} 0100$ $40421998000600019 \& \operatorname{lng}=\mathrm{en} \& \mathrm{nrm}=\mathrm{iso}>$. Acesso em: 25 June 2009. doi: 10.1590/ S0100-40421998000600019.

AlLERY LA. Educational games and structured experiences. Medical Teacher 2004, 26:504-505.

MAGALHAES, CR. O jogo como pretexto educativo: educar e educar-se em curso de formação em saúde. Interface (Botucatu), Botucatu, v. 3, Selected Edition2007. Disponível em: $<$ http://socialsciences.scielo.org/scielo.php? script $=$ sci_ arttext\&pid $=$ S1414-32832007000100030$\& \operatorname{lng}=$ pt\&nrm $=$ iso $>$. Acesso em: 03 Jan 2008

Endereço para Correspondência:

João Miguel de Almeida Silva joaomiguel87@yahoo.com.br

Rua 6, nº 111 - Barreira Cravo

Volta Redonda - RJ

CEP: 27.285-260

Informações bibliográficas:

Conforme a NBR 6023:2002 da Associação Brasileira de Normas Técnicas (ABNT), este texto científico publicado em periódico eletrônico deve ser citado da seguinte forma: SILVA, João Miguel Almeida da; CANEDO, Rafael Vieira; ABRANTES, Thomas Alves de Souza; SOUZA, Renata Almeida de; SANTOS, Rafael Teixeira dos; UTAGAWA, Claudia Yamada. Quiz de Genética e Biologia Molecular - A experiência discente e docente no desenvolvimento de um material didático. Cadernos UniFOA. Volta Redonda, ano IV, n. 11, dezembro 2009. Disponível em: <http://www.unifoa.edu.br/cadernos/edicao/11/65.pdf> 